\title{
Emir ŠEČIĆ
}

Institut za društvena i religijska istraživanja u Tuzli

E-mail: secic.emir@hotmail.com

Stručni rad/Professional article

UDK/UDC: 94:2-3:304(497.6 Srebrenica)"18/20" (047)

DOI: https://doi.org/10.52259/historijskipogledi.2021.4.6.395

\section{Izvještaj sa Naučne konferencije „ALIMI SREBRENICE I NJIHOVA ULOGA U DUHOVNOM I DRUŠTVENOM ŽIVOTU BOŠNJAKA", Srebrenica, 6. juli 2021. godine}

Institut za društvena i religijska istraživanja je u utorak, 6. jula 2021. godine u Srebrenici organizirao naučnu konferenciju pod nazivom Alimi

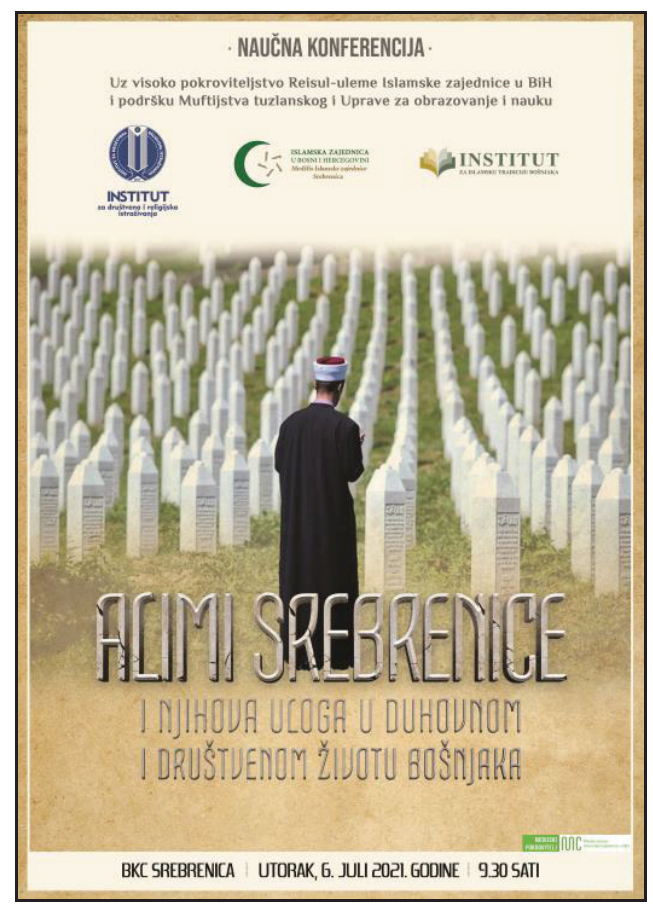

Prilog 1. Plakat naučne konferencije.

Srebrenice i njihova uloga $u$ duhovnom $i$ društvenom životu Bošnjaka. Konferencija je organizirana pod visokim pokroviteljstvom reisul-uleme Islamske zajednice u Bosni i Hercegovini dr. Husein-ef. Kavazovića, a održana je u okviru programa obilježavanja 26. godišnjice genocida nad Bošnjacima zaštićene zone UNa Srebrenica. Konferenciju su podržali Muftijstvo tuzlansko i Uprava za nauku i obrazovanje Rijaseta Islamske zajednice. Suorganizatori konferencije, koja je održana u Bosanskom kulturnom centru u Srebrenici, su Institut za islamsku tradiciju Bošnjaka u Sarajevu i Medžlis Islamske zajednice Srebrenica.

Ovoj naučnoj konferenciji prisustvovali su izaslanik Reisul-uleme muftija tuzlanski Vahid-ef. Fazlović, muftija zagrebački dr. Aziz-ef. Hasanović, potpredsjednik bosanskohercegovačkog entiteta RS mr. Ramiz Salkić, 
Zamjenik načelnika opštine Srebrenica gosp. Hamdija Fejzić, direktori ustanova, univerzitetski profesori, istraživači i Srebreničani.

\section{Naš dug prema alimima Srebrenice}

Rasvjetljavanje uloge alima Srebrenice u duhovnom i društvenom životu Bošnjaka, a što je cilj ove naučne konferencije, jeste istovremeno i odavanje priznanja svima njima, ali i ispunjavanje dijela našeg trajnog duga prema Bošnjacima u Srebrenici, kazao je Vahid-ef. Fazlović, muftija tuzlanski. Istakao je da ovaj naučni skup predstavlja vrijedan doprinos memorizaciji genocida, a posebno iz razloga što je predviđeno predstavljanje imama šehida genocida nad Bošnjacima međunarodno zaštićene zone Srebrenica, u kojoj su oni, suočeni s teškim i neizvjesnim prilikama, u našem narodu obavili iznimno značajnu ulogu. Muftija Fazlović je podsjetio da je Srebrenica iznjedrila alime kojima u redovima bosanske uleme pripada visoko mjesto.

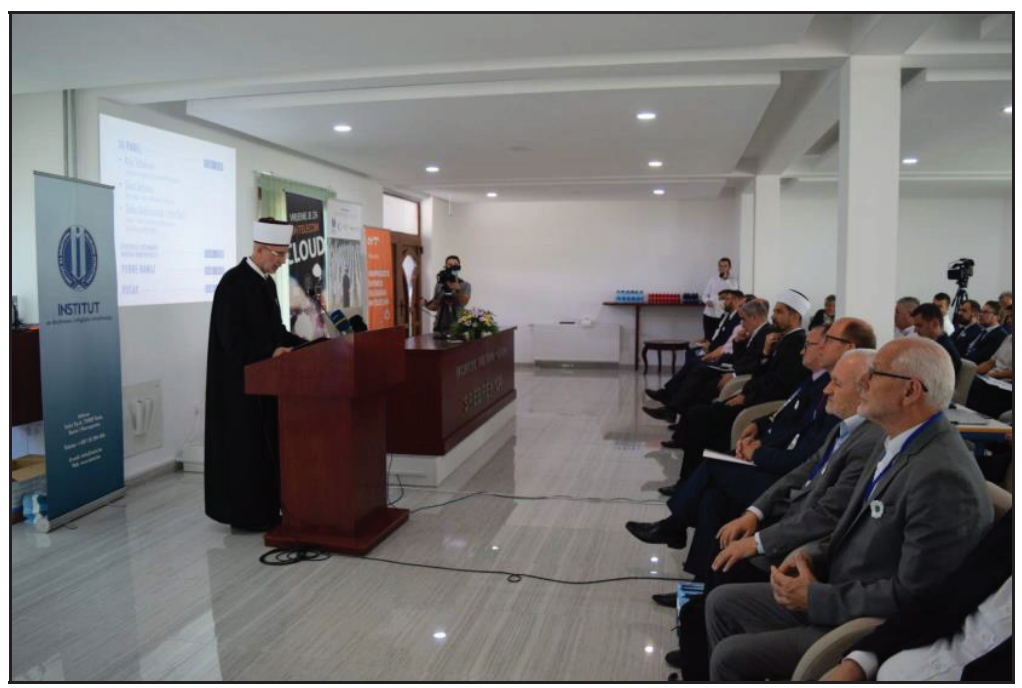

Prilog 2. Obraćanje tuzlanskog muftije Vahid-ef. Fazlovića.

Direktor Instituta za društvena i religijska istraživanja dr. Šefko Sulejmanović je istakao da je dvanaest naučnika uzelo učešće u ovoj konferenciji. Pored istraživača sa tri Instituta, učešće su uzeli i dali svoj doprinos da ova konferencija bude uspješna i naučni radnici sa nekoliko fakulteta i organa Islamske zajednice. Cilj ovog naučnog skupa je rasvjetljavanje i afirmiranje duhovne i društvene uloge alima Srebrenice, uloge alima u borbi protiv fašizma $\mathrm{u}$ vrijeme Drugog svjetskog rata te stradanje imama u genocidu nad Bošnjacima zaštićene zone UN-a Srebrenice (19931995), kazao je direktor Sulejmanović. 
Prof. dr. Dževad Hodžić, direktor Uprave za obrazovanje i nauku Rijaseta Islamske zajednice, ovom je prilikom kazao da se značaj konferencije ogleda u više segmenata. „Konferencija je važna zato što imamo dug prema alimima Srebrenice, važna je zbog ljudi koji ovdje danas žive. Ovdje dajemo svoju podršku životu i povratku u Srebrenici. Naravno, ima i simboličko značenje jer se odvija u vrijeme obilježavanja 26. godišnjice genocida nad Bošnjacima“, kazao je dr. Hodžić.

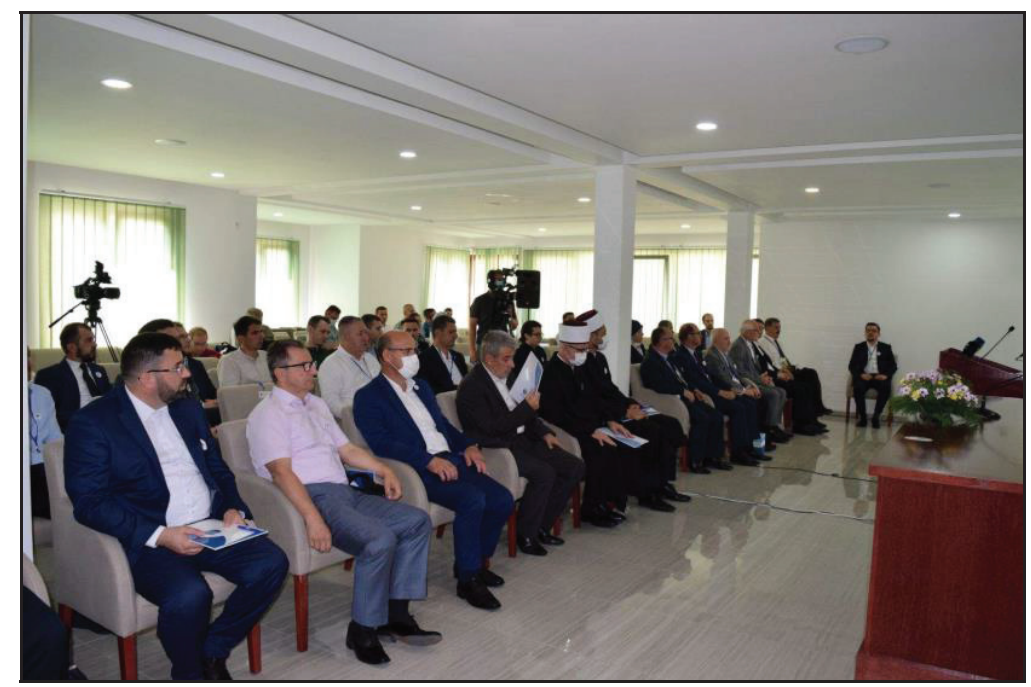

Prilog 3. Učesnici i gosti na Naučnoj konferenciji.

Glavni imam Medžlisa Islamske zajednice Srebrenica Damir-ef. Peštalić je rekao da je u Srebrenici uspostavljen život, ali da ima još mogućnosti koje se mogu i trebaju iskoristiti, te da ljudima Srebrenice održavanje ove konferencije i dolazak istraživača i naučnika predstavlja značaju moralnu podršku. „Velika je stvar da se danas u Srebrenici održava ova konferencija, koja potvrđuje upostavljeni život. Srebrenica je neistražen grad, Srebrenica je nepoznanica u mnogim stvarima pa i kada su u pitanju alimi koji su živjeli u Srebrenici, stoga je značaj ove konferencije zaista velik“, kazao je glavni imam Peštalić.

\section{Alimi koji su poznatiji u svijetu nego u Bosni i Hercegovini}

Programom konferencije planiran je rad u tri panela, kojim su predsjedavali direktor Instituta za društvena i religijska istraživanja dr. Šefko Sulejmanović, direktor Instituta za islamsku tradiciju Bošnjaka dr. Ferid Dautović te profesorica Fakulteta islamskih nauka dr. Zehra Alispahić.

Uvodno predavanje na temu Uloga uleme $u$ duhovnom $i$ društvenom životu Bošnjaka održao je prof. dr. Dževad Hodžić, direktor Uprave za 
obrazovanje i nauku Rijaseta Islamske zajednice u Bosni i Hercegovini. On je u jednom veoma inspirativnom izlaganju govorio o učenim i uspješnim Srebrenčanima koji su više poznati u svijetu nego u Bosni i Hercegovini. Posebno je akcentirao životnu ulogu dr. Ahmeda Smajlovića i arhitekte Selmana Selmanagića.

Prvi izlagač u okviru prvog panela bio mr. Kemal Nurkić, direktor Zavoda za zaštitu i korištenje kulturno-historijskog i prirodnog nasljeđa Tuzlanskog kantona. On je govorio na temu Imami srebreničkog kadiluka $i$ njihova uloga u društvenom životu Bošnjaka. Mr. Nurkić je prezentirao popise džemata srebreničkog kadiluka krajem 19. stoljeća. Posebno mjesto na tim popisima imali su imami džemata čija je uloga u tom periodu bila veoma značajna u društvenom životu muslimanskog stanovništva.

Dr. sc. Ferid Dautović, direktor Instituta za islamsku tradiciju Bošnjaka, govorio je na temu Ulema Srebrenice u izvještaju Dž. Čauševića iz 1909. godine. On je govorio o vjerskim prilikama i djelovanju imama srebreničkog kraja analizirajući izvještaj Džemaludin-efendije Čauševića koji je posjetio Srebrenicu te godine.

U okviru ovog panela treće predavanje je održao prof. dr. Sead Selimović, šef Odsjeka za historiju Filozofskog fakulteta u Tuzli. On je govorio na temu Društveno-političke prilike u Srebrenici između dva svjetska rata s posebnim akcentom na djelatnost imama. Autor je naglasio da je suštinski dio ovog rada usmjeren na specifičnost društveno-političkog ambijenta na prostoru Srebrenice, te na koji način su imami djelovali u tom specifičnom periodu.

Dr. sc. Senija Milišić sa Instituta za historiju Univerziteta u Sarajevu je govorila na temu Antifašistička orijentacija alima u Drugom svjetskom ratu. Autorica je u jednom energičnom i veoma inspirativnom obraćanju govorila o izazovima koji su se nalazili pred ulemom u njihovoj borbi protiv fašizma tokom Drugog svjetskog rata.

Posljednji izlagač u okviru prvog panela bio je mr. Omer Zulić, direktor Arhiva Tuzlanskog kantona. On je izložio rad na temu Odnos komunističke vlasti prema Islamskoj vjerskoj zajednici u tuzlanskoj oblasti sa akcentom na područje Srebrenice (1945-1953), koga je zajedno sa prof. dr. Izetom Šabotićem, redovnim profesorom Filozofskog fakulteta Univerziteta u Tuzli, pripremio za ovu konferenciju. Mr. Zulić je u svom izlaganju kazao da je završetkom Drugog svjetskog rata i dolaskom komunista na vlast Islamska zajednica u Bosni i Hercegovini bila u teškoj poziciji sa nizom finansijskih i opreativno-funkcionalnih problema. Nova vlast je nametnula čitav set represivnih mjera i zakona, čime je dodatno oslabila Islamsku zajednicu. Ovakav tretman negativno se odrazio na vjerske službenike čiji je život sveden na puko preživljavanje.

Drugi panel je svojim izlaganjem otvorio prof. dr. Adib Đozić. On je govorio na temu Alimi porodice Đozić iz Srebrenice. Tokom svog izlaganja govorio je o najistaknutijim alimima iz ove poznate srebreničke porodice koji 
su dali veliki doprinos u duhovnom i društvenom životu Srebrenice ali i u drugim gradovima gdje su živjeli i djelovali u svojoj višedecenijskoj misiji.

Mr. sc. Muharem Omerdić, dugogodišnji vjersko-prosvjetni referent Rijaseta Islamske zajednice u Bosni i Hercegovini, govorio je o Životu $i$ djelu $d r$. Ahmeda Smajlovića. Prisjećajući se najupečatljivijih epizoda iz života dr. Smajlovića, na veoma zanimljiv i emotivan način je govorio o jednom od najznačajnijih alima 20. stoljeća na području bivše Jugoslavije pa i šire.

Prof. dr. Zehra Alispahić sa Fakulteta islamskih nauka iz Sarajeva je govorila o Naučnom i pedagoškom radu dr. Mesuda Hafizovića. Autorica se u veoma zanimljivom izlaganju prisjetila najvažnijig segmenata iz života prof. Hafizovića. Posebno je akcentirala profesorov pedagoški rad u Gazi Husrevbegovoj medresi i na Fakultetu islamskih nauka. Bogata bibliografija profesora Mesuda Hafizovića svrstava ga među najrelevantnije alime i naučnike koje je Islamska zajednica baštinila. Genocid u Srebrenici, u kojem su ubijeni najbliži članovi njegove porodice, ostavio je velike posljedice na njegov život i mnogo uticao na njegovu preranu smrt.

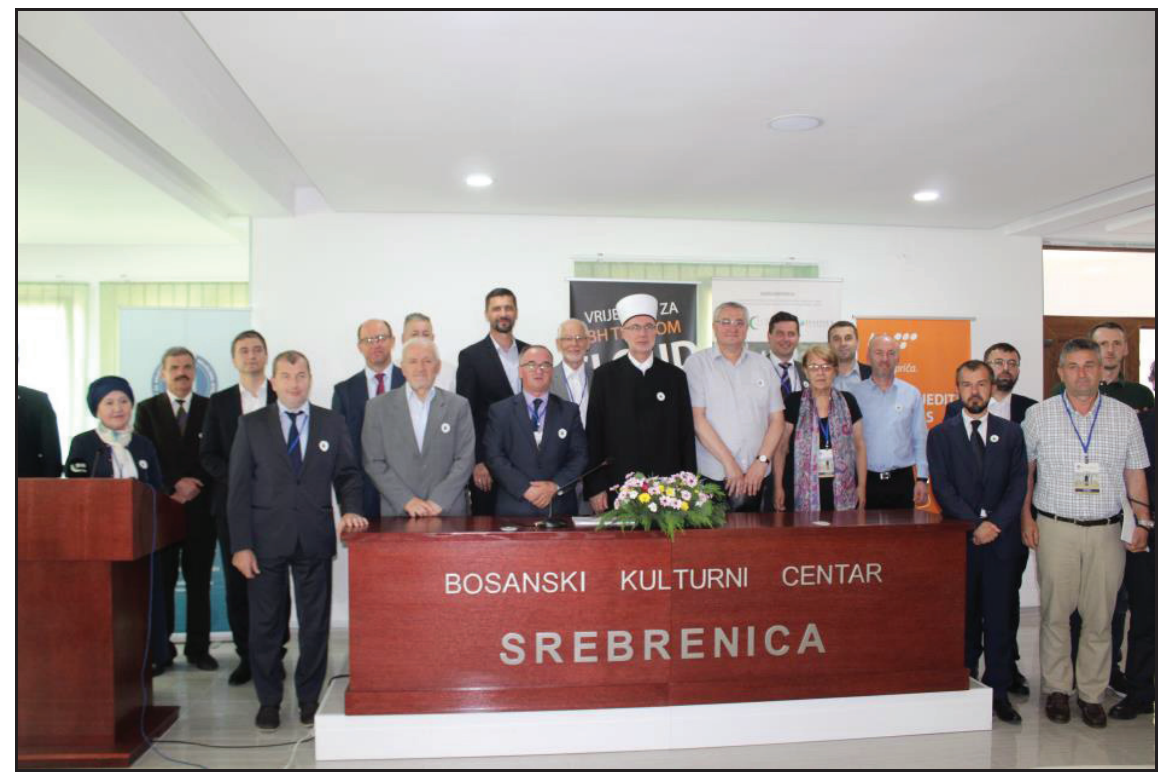

Prilog 4. Zajednička fotografija učesnika Naučne konferencije.

U okviru ovog panela rad je izložio i prof. dr. Mustafa Hasani sa Fakulteta islamskih nauka u Sarajevu. On je prezentirao rad na temu Naučni $i$ pedagoški rad dr. Ibrahima Džananovića. Autor je govorio o životnom putu dr. Džananovića ističući njegove posebne kvalitete $u$ radu sa učenicima i studentima, ali i njegovo naučno i stručno profiliranje, čiji su tragovi ostali zapisani između korica nekoliko knjiga kao i na desetinama objavljenih tekstova. Čvrstoća ljudskog karaktera i neraskidiva veza sa rodnom 
Srebrenicom su crte iz njegovog života koje su posebno krasile ovog uglednog alima.

U okviru trećeg panela govorila su trojica izlagača. Panel je svojim izlaganjem otvorio prof. Alija Tabaković. On je govorio na temu Tradicija imamske službe porodice Hasanović. Autor je u svom izlaganju istaknuo da je ova porodica u posljednjih 100 godina iznjedrila 13 imama koji su dali veoma značajan doprinos u duhovnom i društvenom životu muslimana. Jedan od najistaknutijih alima iz ove porodice je aktuelni muftija zagrebački dr. Aziz-ef. Hasanović.

Dr. sc. Sead Seljubac je govorio na temu Alim $i$ šejh - šehid Mehmedef. Hafizović. Dr. Seljubac je govorio o životnom putu i specifičnim metodama koje je koristio u svome radu i djelovanju Mehmed-ef. Hafizović. Njegova imamska uloga i misija na planu duhovnog uzdizanja muslimana imala je veliki značaj za vrijeme u kojem je živio. Svoj život je položio u odbrani domovine od agresije. Dobitnik je jednog od najviših ratnih priznanja Zlatni ljiljan.

Dr. sc. Šefko Sulejmanović, direktor Instituta za društvena i religijska istraživanja iz Tuzle, prezentirao je rad na temu Imami - žrtve Genocida nad Bošnjacima Srebrenice (1992-1995), koga je pripremio zajedno sa prof. Emirom Šečićem. Dr. Sulejmanović je u svom izlaganju govorio u ulozi imama u Srebrenici tokom agresije na Bosnu i Hercegovinu. Na poseban način i sa velikim respektom je naglasio da je 27 imama ubijeno u genocidu u Srebrenici jula 1995. godine.

\section{Planirano je publiciranje tematskog zbornika radova}

Nakon što su svi izlagači prezentirali svoje radove na ovoj naučnoj konferenciji, uslijedila je diskusija. Posebno zapažena diskusija bila je muftije zagrebačkog dr. Aziza-ef. Hasanovića. On se zahvalio organizatorima konferencije na uspješnoj organizaciji, učesnicima konferencije na dobro pripremljenim referatima, a onda se prisjetio nekoliko srebreničkih alima iz svog djetinjstva, od kojih se posebno isticao dr. Ahmed Smajlović i njegov autoritet. Naučna konferencija je završena zajedničkim ručkom u prostorijama Medžlisa Islamske zajednice Srebrenica. Organizatori ove naučne konferencije planiraju i publiciranje rezultata istraživanja u tematskom zborniku radova. 